\title{
Erratum to: New Methods for the Preparation of Nanosized Metal Coordination Polymers
}

\author{
Dina M. Fouad ${ }^{1}$ - Aref A. M. Aly ${ }^{1}$ Mervat I. A. Mohammed ${ }^{2}$
}

Published online: 20 January 2017

(C) Springer Science+Business Media New York 2017

\section{Erratum to: J Polym Environ}

DOI 10.1007/s10924-016-0781-8

In the title of the original publication, the word "of" is missing between the words "Preparation" and "Nanosized". Also, Figs. 6 and 7 should be interchanged. The corrected article title, Figs. 6 and 7 are published with this erratum.

The online version of the original article can be found under doi:10.1007/s10924-016-0781-8.

Dina M. Fouad

dinafouad93@hotmail.com

1 Chemistry Department, Faculty of Science, Assiut University, Assiut, Egypt

2 Chemistry Department, Faculty of Science (New Valley Branch), Assiut University, Assiut, Egypt 


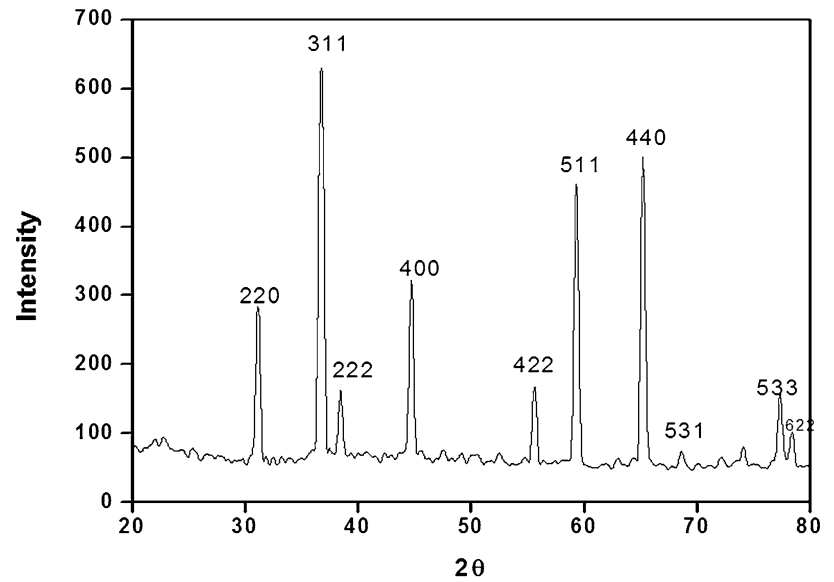

Fig. 6 The XRD of $\mathrm{Co}_{3} \mathrm{O}_{4}$ nanoparticles

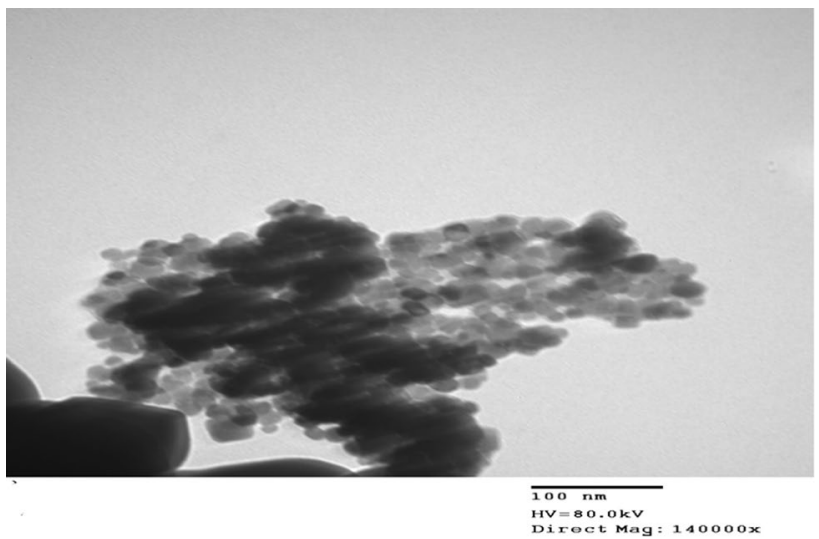

Fig. 7 TEM of $\mathrm{Co}_{3} \mathrm{O}_{4}$ 